\title{
Research on Cultivation Mode of Engineering Practical Ability Based on Post Simulation - Taking the hydrology and water resources en- gineering major in Tianjin Agricultural Universi- ty as the example
}

\author{
Lizhen Wang, Shuhong Sun, and Ling Liu \\ School of Water Conservancy Engineering, Tianjin Agricultural University, 300384 Tianjin, China
}

\begin{abstract}
This article aims at exploring the cultivation mode of engineering practical abstract based on post simulation to provide scientific and reasonable basis for talent cultivation. According to survey of hydrology and water resources industry, we determine the talent specification and its post group, analyze the relationship of post group and course system, reform the teaching system and relevant condition and integrate the engineering practice of post simulation. Finally, we make an analysis and verification on the cultivation effect in different perspective and find that each ability of students cultivated from this mode has been greatly improved, by which we confirm that the cultivation mode of engineering practical ability based on post simulation has an important meaning for cultivating talents in engineering faculty.
\end{abstract}

Keywords. post simulation; engineering practical ability; cultivation mode

The college student cultivated by traditional teaching mode has a narrow professional fields, relatively weak experimental and practical skills and insufficient cultivation of innovative ability and comprehensive quality, especially of hardship bearing, social responsibility and social acceptability; the cultivation mode is single and not helpful to cultivation of innovative and practical ability for students. So it is required for the university to change the education concept to further perfect the teaching cultivation mode. Therefore, reforming the cultivation mode of engineering talent is a breakthrough for improving the engineering education.

With reference to CDIO engineering educational concept, we should cultivate practical applied talents in water resources engineering and professional technical talents meeting the need of water resources industry in coastal water-deficient area through being oriented by requirement of industrial talent and taking the engineering quality and engineering practical ability requirement as the ultimate purpose. In recent years, more and more people in enterprises think the graduate in engineering faculty almost has no ability required in modern 
engineering environment though they master the technology, so we just have millions of "high-intelligence students" instead of "high-creativity students". How to convert the "high-intelligence students" to "high-creativity students" and let them have the teamwork spirit, communication ability and control power over multiple disciplines and big system necessary for growth in modern engineering environment has become the hot issue of reform in Chinese higher engineering education.

\section{Determine the talent specification in hydrology and water re- sources engineering by survey}

The modern water resources cause has a new connotation, and the water resources staffs also have corresponding ability. The reform of cultivation mode is rather important to cultivate the suitable applied engineering technical talents according to the development requirement of modern water resources cause. Determine the talent specification in hydrology and water resources engineering and cultivation target positioning, as well as widely develop the industrial survey to cultivate the practical innovative applied talents for water resources engineering. The surveys on water resources system in Tianjin and part of those in North China have been developed. It is found from the survey that the graduate from hydrology and water resources major mainly has 9 post groups to face:

1) Planning, engineering management, water resources management, water administration, water supply and drainage technology and management group in provincial water resources department.

2) Post group of water resources design unit, and the design objective is mainly the intermediate water engineering.

3) Technical or business management post group in large and intermediate construction, supervision and other units, such as constructor, budgeter and supervisor.

4) Group of posts in hydrology, water resources and water environment monitor technology and posts in technical management in hydrological survey unit and water resources management unit.

5) Technical or management post group in legal units of basic water resources engineering project.

6) Post group in water-power station unit.

7) Post group in water resources engineering planning, construction, operation technology management, water supply and drainage management, water resources, water environment management, water-saving irrigation and water administrative law enforcement in county level.

8) Post group in water resources and water-power engineering management unit, reservoir management unit, river course management unit, irrigated area management unit, water pumping or drainage pump station.

9) Post group of basic water management, basic water supply enterprise, sewage treatment enterprise, water conservation management, basic water environment monitor and management.

We have made a survey on knowledge and ability requirement of 9 post groups, including the planning, design, construction and management of water resources industry, where the basic quality abilities include: ideological quality, physical quality, linguistic ability, computer ability, mathematic calculation ability; professional abilities include: surveying and mapping ability, calculation and analysis ability, planning and design ability, ability to manage the engineering construction operation surface, construction organization and engineering operation. We have preliminarily determine the specification of applied talent in "hydrology and water resources engineering major" according to survey material and take the "engineering practical ability" as the reference for applied talent. 


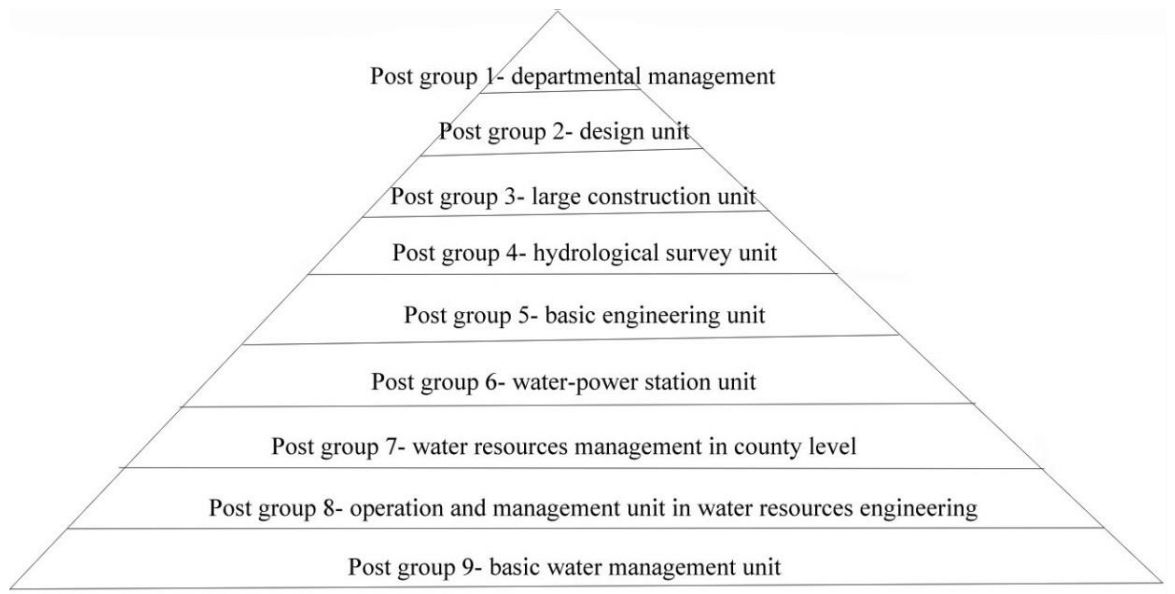

Figure 1. Relationship among post groups.

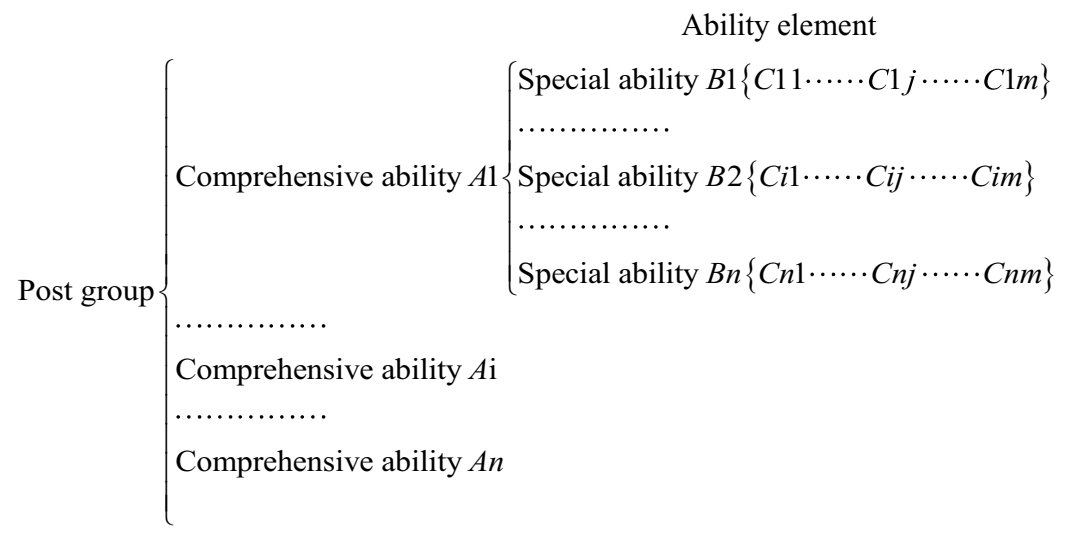

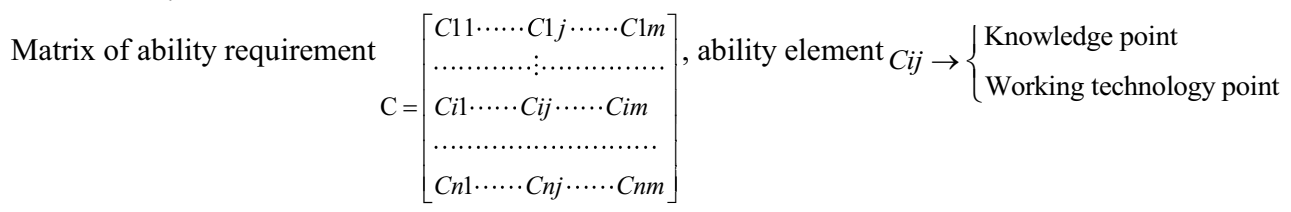

Corresponding

Theoretical course

Knowledge matrix $\left[\begin{array}{l}E 11 \cdots \cdots E 1 j \cdots \cdots E 1 m \\ \cdots \cdots \cdots \cdots \cdots \cdots \cdots \cdots \\ E i 1 \cdots \cdots E i j \cdots \cdots \cdot E \text { Eim } \\ \cdots \cdots \cdots \cdots \cdots \cdots \cdots \cdots \\ E n 1 \cdots \cdots \cdot E n j \cdots \cdots E n\end{array}\right] \rightarrow\left[\begin{array}{c}D 1 \\ \cdots \\ D i \\ \cdots \\ D n\end{array}\right]$

Corresponding

Practical stage

Matrix of working technology point $\left[\begin{array}{l}E 11 \cdots \cdots E 1 j \cdots \cdots E 1 m \\ \cdots \cdots \cdots \cdots \cdots \cdots \cdots \cdots \cdots \\ E i 1 \cdots \cdots E i j \cdots \cdots \cdot E i m \\ \cdots \cdots \cdots \cdots \cdots \cdots \cdots \cdots \cdots \\ E n 1 \cdots \cdots E n j \cdots \cdots E n m\end{array}\right] \rightarrow\left[\begin{array}{c}F 1 \\ \cdots \\ F i \\ \cdots \\ F n\end{array}\right]$

Figure 2. Matrix of knowledge point and ability point. 
We may use a pyramid distribution map to represent the above 9 post groups according to the number and working relationships of employers (see Figure 1). Determine the comprehensive ability module (project simulation), special ability module (scenario simulation) and ability element (know-how). We have analyzed the comprehensive ability module, the special ability module and the ability element required for professional posts of water resources engineering. Construct a matrix of knowledge point and ability point according to know-how of ability element (Figure 2) to generalize and determine the theoretical teaching system and practical teaching system by taking the ability cultivation as the basic unit.

In the cultivation of application ability, we are "practicality-oriented" to develop a survey over talent specification and ability requirement for talent market, and we generalized that we should cultivate the application ability in planning, design, construction, market of water resources engineering and efficient water usage technology for agriculture in modern metropolitan to meet the knowledge and ability system required for posts. In talent cultivation mode, we modify the cultivation scheme to cultivate senior applied talent by taking the engineering ability requirement as the ultimate purpose; facilitate the improvement of undergraduate teaching quality and strengthen the cultivation of application ability and innovation ability by disciplinary advantages. We focus on cultivation of manipulative ability and adaptation ability for students to better satisfy the needs of employer on engineering technical talents; we concentrate on combination of industrial production and teaching, take the evidence with the help of skill certificate and realize zero transition from school to working post; we realize cultivation purpose by improving the experimental teaching condition and situation of teachers team.

\section{Relationship of post group and course system}

In consideration of employment direction of graduate, most of county-level water resources department and those in north area need the applied talent in fixed and engineering technology mode; there are few course set about engineering construction technology in "hydrology and water resources engineering major" in domestic colleges, so a module of engineering construction course is added to the course setting for this major. We optimize many practical stages, such as course experiment, course design, teaching practice (including cognitive practice) and production practice and graduation design according to conditions of know-how of comprehensive ability, special ability and ability element. The course system has a times and modular features and focuses on ability cultivation.

The survey and analysis on corresponding relationship of post group and each kind of ability are shown in Figure 3.

\section{Cultivation method and means reform}

Teaching method is the whole process throughout the teaching and the important condition for relationship teaching effect and teaching quality. The traditional teaching is a teaching mode centered on knowledge, and we cannot wholly deny the spoon-feeding education. But this teaching method actually has some disadvantages for teaching of engineering major course.

Transform the practical stage into detailed project based on practical stage of "general project-simulation-based" talent cultivation mode, and explore the mode, method and procedure of project-based practical teaching by taking the "project-simulation-based" practical teaching mode as the carrier. The "project" is designed by teaching and research room and professional laboratory, which may be engineering planning, design of water resources engineering buildings, engineering construction, operation management of waterworks, sur- 
CYHF 2015

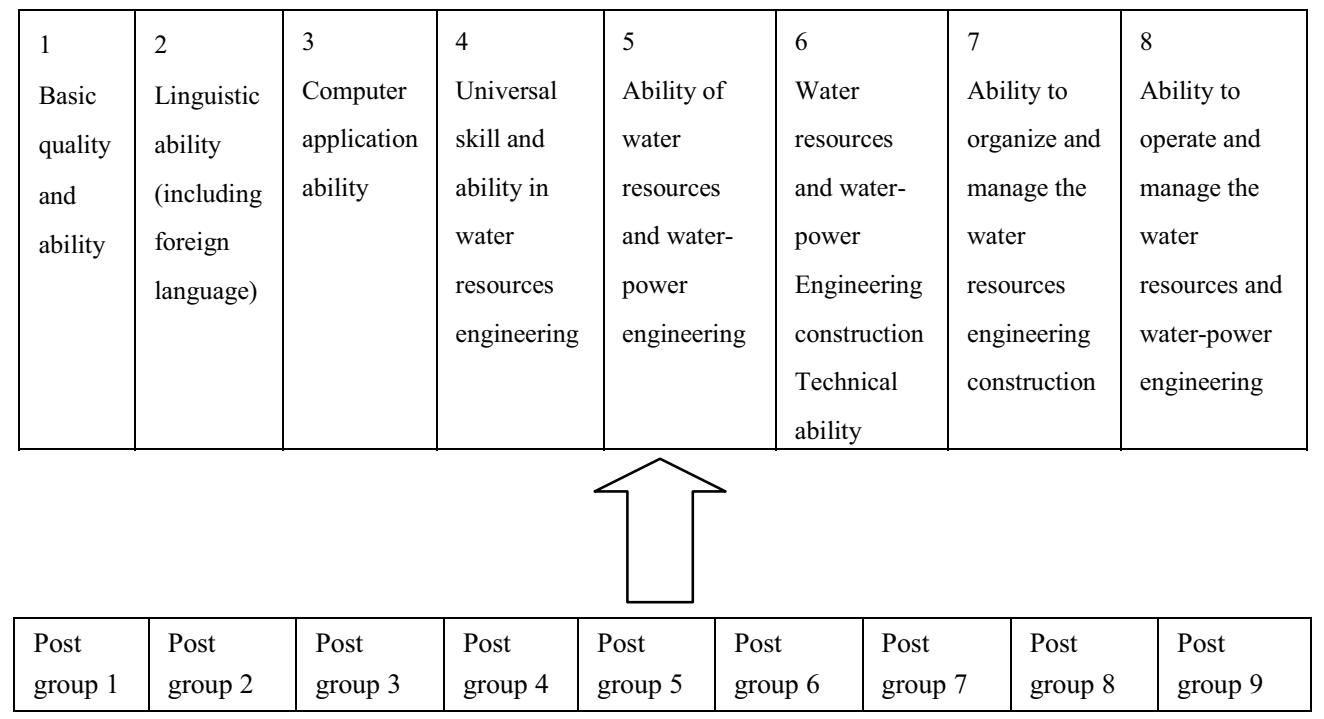

Figure 3. Corresponding relationship of each ability and post group

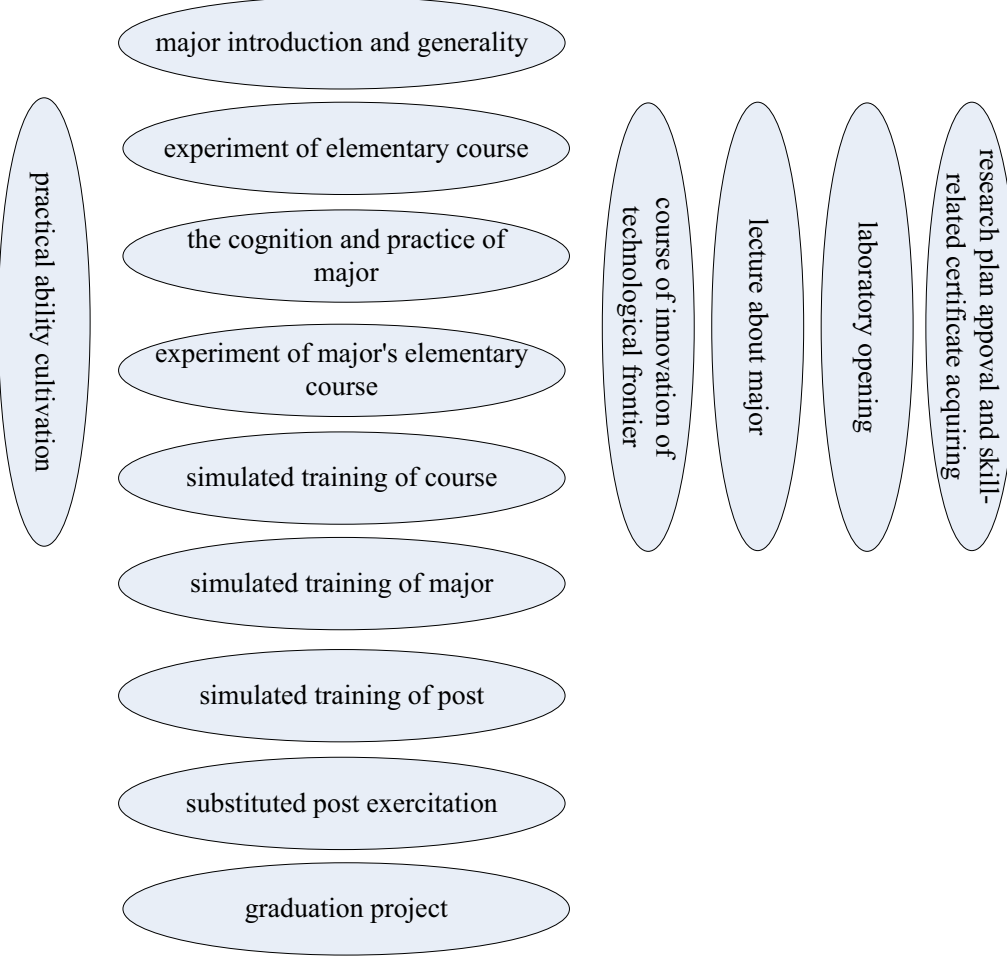

Figure 4. System of engineering quality, engineering practical ability and innovative ability.

veying and mapping task, experimental task, detection task and so on. By taking each professional laboratory as the contract award of "Party A", the student (group) may accept the project task released by professional laboratory, or by bidding within their own professional field. Then the student may be independently responsible for project organization, design 
and implementation, as well as the summary of project accomplishing report. The teacher may be responsible for assessment on conditions of project accomplishment. The "project simulation" practical teaching mode is in consistency with CDIO higher engineering educational concept recommended by international engineering education field that takes the whole process of Conceive, Design, Implement and Operate as the carrier. We will further digest and learn the advanced engineering education concept, try hard to cultivate the engineering practical ability for students to realize cultivation of "understanding and organizational ability, action ability, manipulative ability and accomplishment ability", as well as strengthen the business and management ability for students.

In teaching means, we aim at cultivating first-rate innovative applied talent, attach importance to improving innovative ability and humanity, cultivate practical applied talents in water resources engineering and professional technical talents meeting the need of water resources industry in coastal water-deficient area, and construct a cultivation system of engineering quality, engineering practical ability and innovative ability (Figure 4). For the purpose of practice, we cultivate the application ability in planning, design, construction, market of water resources engineering and efficient water usage technology for agriculture in modern metropolitan to meet the knowledge and ability system required for posts.

\section{Cultivation effect (reform effect)}

Through this reform, the comprehensive quality, ability and social assessment on the students (including expected talent cultivation effect) are greatly improved, mainly reflected in the following contents:

\subsection{Deep foundation and broad extension}

The actual level of student's basic theory and basic skill has been constantly improved. In learning and cultivation of basic theory and basic skill for students, we implement many feasible measures as follows: set interdisciplinary crossing basic courses; facilitate the construction and use of practical teaching base inside and outside the college according to the features of each major; employ external experts to be our teachers in college; employ guest professor; let students go outside the school and be at the frontline of production practice; strengthen on-line teaching and so on. The implementation of above measures realizes the organic combination of classroom and practical teaching, which consolidates and deepens the mastering and understanding of basic theory, tamps the foundation, and strengthens the innovative and practical ability for students.

\subsection{Innovation spirit of student is constantly improved}

For the purpose of cultivating innovative applied talents in engineering practice, we positively develop communication and discussion; we develop each kind of special scientific lecture to improve student's interest and enthusiasm in the major they learn; we let them go outside the classroom, participate in practice, extend the view and broaden the thinking in practice, and learn to find, analyze and solve the problems in practice. The state has invested many special funds for scientific innovative career startup project for college students, and openly advocates nationwide career startup and innovation. The above measures cultivate the innovative spirit for students, and their practical ability has been usually improved. 


\subsection{Engineering practical ability of students is constantly improved}

Strengthen the ability cultivation in graduate design (thesis) stage, focus on practicality in topic selection and use first-hand data. $90 \%$ of graduates in hydrology and water resources engineering major take actual engineering background data and teacher scientific research topic as their direction of topic selection. The graduate practice is implemented by post shift practice, basic practice and other means, which perfectly train the comprehensive ability and consolidate four-year knowledge in undergraduate study for students.

\subsection{Strive to realize comprehensive growth for students cultivated in experi- mental area}

The students cultivated by project-released educational mode and CDIO process oriented teaching mode have strong engineering practical ability, improved cooperation and teamwork spirit with others. In management ability and quality, the students cultivated by allround cultivation and training may get a comprehensive cultivation and growth, and meet the demand of global all-in-one economic development on fixed talent.

\subsection{Assessment of employer and stakeholder on student performance after graduation}

The employment conception is greatly changed with the development of market economy, and the talent quality standard also goes through radical transformation. Many employers will focus more on actual working ability, interpersonal communication ability and teamwork spirit, even the image and quality instead of scores and grades when selecting graduates. They tend to arrange one person in multiple posts, which produces a new requirement for our engineering education reform.

The graduates subject to post-simulation-based engineering education cultivation win the praise from employers by their excellent performance in various aspects. According to feedback from employers, "the students graduated from water resources engineering major in Tianjin Agriculture College have strong working ability, fast adaptation, honesty, and can bear hardship and be helpful".

\section{Envision}

The post-simulation-based engineering education cultivation mode is a good practical method to cultivate an engineer, which has been used in colleges of many countries such as America, Japan and Australia. Our Chinese key universities have obtained successful experience through practice. We should make research and practice on ideology, purpose, content, method, teaching conditions of quality assessment standard and other elements for talent cultivation mode, and need the comprehensive overall design and reform to achieve the desirable talent cultivation purpose.

\section{Acknowledgment}

Project source: Educational Teaching Research and Reform Project from Tianjin Agriculture College. Research on Cultivation Mode of Engineering Practical Ability Based on Post Simulation 


\section{References}

1. Tao, Y.F., Shang. C.H. 2006. Inspiration of outline to higher engineering educational innovation. Chinese Higher Education Research, 11: 81-83.

2. Wang, S.W., Hong, C.W. 2009. CDIO: Classic mode of MIT engineering educationbased on interpretation of CDIO course outline. Research on High School Science and Engineering, 28(4): 116-119.

3. Shi, D.M. 2008, Construction of practical teaching system of undergraduate hydrology and water resources. Journal of Southwest Agricultural University (Social Science Edition), 6(1): 192-195.

4. Wang, Q.R., Deng. Z.M. Chen, W. et al. 2008. Scientific orientation and cultivation of applied undergraduate talents. Journal of Guangdong University of Technology (Social Science Edition), 8(S): 1-2.

5. Sun, A.D. 2008. Thinking about talent cultivation scheme in applied undergraduate college. Journal of Heilongjiang College of Education, 27(2): 45-47.

6. Liang, H.D. 2008. Practice and exploration of cultivating applied talents meeting the local actual need. Journal of Taizhou College, 30(3): 48-51.

7. Jiang, S.Q. 2008. EIP-CDIO: Reform of cultivation mode of higher engineering education. China Electric Power Education (Educational Theory and Practice), 10: 32-33.

8. Lin, Y.Z. 2008. Analysis on CDIO higher engineering education mode. Journal of Harbin (Social Science Edition), 29(4): 137-140.

9. Li, D., Li, F.H., Fang, X.F. 2008. Exploration of practical teaching of hydrology and water resources engineering major. Journal of Shijiazhuang University of Economics, 31(4): 127-129.

10. Sun, S.G., Jiang, X.H. 2008. Thinking about cultivation of applied talent in hydrology and water resources engineering major. Journal of Changchun Institute of Technology (Social Science Edition), 9 (3): 81-82.

11. Zhang, M.L. 2009. Discussion on machinery engineering education reform based on CDIO engineering educational concept. Educational Research, Shanghai University of Engineering Science, 3: 26-30.

12. Wang, L.Z., Sun, S.H. 2010. Preliminary exploration of hydrology and water resources teaching reform based on ability cultivation. China Electric Power Education, 36: 7576. 